\title{
MATURAÇÃO DE SEMENTES DE ABOBRINHA MENINA BRASILEIRA ${ }^{1}$
}

\author{
SAULO DE TARCIO PEREIRA MARROCOS ${ }^{2}$, MARIA APARECIDA DE MEDEIROS ${ }^{3}$, \\ LEILSON COSTA GRANGEIRO ${ }^{4}$, SALVADOR BARROS TORRES $^{5}$, RAFAELLA RAYANE MACEDO DE LUCENA ${ }^{6}$
}

\begin{abstract}
RESUMO - O objetivo do trabalho foi determinar a maturidade fisiológica de sementes de abobrinha, cultivar Menina Brasileira, em função da idade dos frutos. As sementes foram provenientes de frutos colhidos aos 20, 30, 40, 50 e 60 dias após a antese (DAA). O cultivo das abobrinhas foi realizado no campus central da Universidade Federal Rural do Semiárido (UFERSA), Mossoró, RN, no período de dezembro de 2007 a março de 2008. Após a colheita, os frutos passaram por um período de repouso com posterior extração das sementes, para determinação do teor de água e da massa seca. A qualidade fisiológica foi avaliada por meio dos testes de germinação, primeira contagem de germinação, índice de velocidade de emergência e envelhecimento acelerado. O teor de água das sementes decresceu de 76 a 49\% no período avaliado. Observam-se acréscimos na qualidade fisiológica das sementes com a idade dos frutos, que atingiram a maturidade fisiológica em torno dos 60 DAA, embora sua colheita possa ser realizada entre 50 e 60 DAA.
\end{abstract}

Termos para indexação: Cucurbita moschata, qualidade fisiológica, germinação.

\section{SEED MATURATION IN BUTTERNUT SQUASH, VARIETY MENINA BRASILEIRA}

\begin{abstract}
The objective of this study was to determine the physiological maturity of buttennut squash seeds, cv. Menina Brasileira, in relation to fruit age. Seeds from fruits collected at 20, 30, 40, 50 and 60 days after anthesis (DAA) were used. The squash plants were grown on the central campus of the Universidade Federal Rural do Semiárido, Mossoró, RN - Brazil, from December 2007 to March 2008. The harvested fruits were rested prior to seed extraction and determination of the water content and dry weight. The physiological quality of the seeds was evaluated from tests of germination, germination first count, emergence speed index and accelerated aging. The seed water content decreased from $76 \%$ to $49 \%$ during the study period. The seed physiological quality increased with fruit age, reaching physiological maturity at about 60 DAA. The fruits may be harvested between 50 and 60 DAA.
\end{abstract}

Index terms: Cucurbita moschata, physiological quality, germination.

${ }^{1}$ Submetido em 09/06/2010. Aceito para publicação em 26/10/2010.

${ }^{2}$ Eng Agr, Mestrando em Fitotecnia do Programa de Pós-graduação em Agronomia, UFERSA.; saulotpm@yahoo.com.br

${ }^{3}$ Eng Agr, Mestre em Agronomia, doutoranda do Programa de Pósgraduação em Agronomia, UFERSA; aparecidacn@gmail.com

${ }^{4}$ Eng. Agr., Dr., Prof. Adjunto, Dept. de Ciências Vegetais, UFERSA,
Caixa Postal 137, CEP 59625-900. Mossoró, RN; leilson@ufersa.edu.br

${ }^{5}$ Eng. Agr., Dr., Pesquisador da Empresa de Pesquisa Agropecuária do Rio Grande do Norte (EMPARN) e Prof. Colaborador do Departamento de Ciências Vegetais, UFERSA; sbtorres@ufersa.edu.br

${ }^{6}$ Eng Agr, Mestranda em Fitotecnia do Programa de Pós-graduação em Agronomia, UFERSA; rafaellarayane@hotmail.com 


\section{INTRODUÇÃO}

As cucurbitáceas ocupam lugar de destaque, sendo de ampla aceitação popular, entretanto, apenas um pequeno percentual de sementes dessas espécies é produzido no Brasil, destacando-se a abobrinha (Cucurbita moschata Duch), cultivar Menina Brasileira, com grande importância econômica no Brasil (Casaroli et al., 2009).

A colheita de frutos para fins de extração das sementes em cucurbitáceas é feita normalmente quando os frutos estão maduros, porém, pode ser realizada até mesmo antes do completo amadurecimento, sendo aconselhável um maior tempo antes da abertura e extração das sementes, pois, de fato, essas últimas continuam a se desenvolver no interior do fruto, fazendo com que no período de armazenamento atinjam o seu ponto da maturidade fisiológica, onde a qualidade e a viabilidade das sementes são melhores (Bee e Barros, 1999).

Com relação à maturação fisiológica, esta envolve todo o processo de desenvolvimento do fruto, desde a fertilização até o momento em que as sementes se desligam da planta mãe, deixando de receber fotoassimilados, estando aptas a desempenharem as funções fisiológicas que lhe são inerentes (Carvalho e Nakagawa, 2000).

Em abobrinhas, que apresentam frutos carnosos, a dificuldade está em conhecer a época em que as suas sementes atingem o ponto de máxima qualidade fisiológica. Para essa espécie o processo de maturação das sementes continua após a colheita dos frutos, atingindo níveis máximos de germinação e vigor após serem submetidas a um período de repouso, o qual varia entre as diferentes espécies (Vidigal et al., 2006; Dias et al., 2006).

Diante do exposto, objetivou-se determinar a maturidade fisiológica de sementes de abobrinha, cultivar Menina Brasileira, nas condições de Mossoró - RN.

\section{MATERIAL E MÉTODOS}

O experimento foi conduzido no campus central do Departamento de Ciências Vegetais da Universidade Federal Rural do Semiárido, em Mossoró - RN, durante o período de dezembro de 2007 a março de 2008, em solo classificado como Argissolo Vermelho-Amarelo. Da área experimental foram retiradas amostras de solo, cuja análise química, revelou os seguintes resultados: $\mathrm{pH}$ (água) $=7,3$; $\mathrm{P}=271,96 \mathrm{mg} \cdot \mathrm{dm}^{-3} ; \mathrm{K}=0,3 \mathrm{cmol}_{\mathrm{c}} \cdot \mathrm{dm}^{-3} ; \mathrm{Ca}=6,2 \mathrm{cmol}_{c}$. $\mathrm{dm}^{-3}, \mathrm{Na}=0,46 \mathrm{cmol}_{\mathrm{c}} \cdot \mathrm{dm}^{-3}$ e $\mathrm{Mg}=2,9 \mathrm{cmol}_{\mathrm{c}} \cdot \mathrm{dm}^{-3}$.

O município de Mossoró está situado aos $5^{\circ} 11^{\prime}$ de latitude $\mathrm{S}$ e $37^{\circ} 20^{\prime}$ de longitude WGr e uma altitude de 18 m. O clima da região, segundo a classificação Köppen é 'Bswh', isto é, seco e muito quente, com duas estações climáticas: uma seca que vai, geralmente, de junho a janeiro e uma chuvosa, de fevereiro a maio (Carmo Filho et al., 1991). Os dados meteorológicos da área, coletados no período de condução dos experimentos, encontram-se na Tabela 1.

TABELA 1. Dados meteorológicos da área durantea condução do experimento.

\begin{tabular}{ccccc}
\hline Ano & Meses & UR $(\%)$ & Temperatura $\left({ }^{\circ} \mathrm{C}\right)$ & Precipitação $(\mathrm{mm})$ \\
\hline 2007 & Dezembro & 60.52 & 28.34 & 25.40 \\
2008 & Janeiro & 64.06 & 28.31 & 47.49 \\
2008 & Fevereiro & 62.78 & 28.66 & 5.84 \\
2008 & Março & 76.93 & 26.81 & 247.43 \\
\hline
\end{tabular}

O delineamento experimental utilizado foi 0 inteiramente casualizado, com cinco tratamentos e quatro repetições, sendo os tratamentos constituídos pela idade dos frutos de 20, 30, 40, 50 e 60 dias após a antese (DAA).

No preparo do solo foram realizadas aração e gradagem seguida de sulcamento e adubação de plantio, tendo como base os resultados da análise de solo e recomendação de Cavalcanti (1998). A irrigação foi aplicada com frequência de rega diária, utilizando gotejamento com emissores de
$1,6 \mathrm{Lh}^{-1}$.

As sementes de abobrinhas foram semeadas em bandejas de isopor multicelulares contendo 128 células, utilizando-se o substrato comercial PlantMax ${ }^{\circledR}$. Aos 14 dias após a semeadura, realizou-se o transplantio das mudas (com duas folhas verdadeiras), sendo plantadas no espaçamento de 2,0 $\mathrm{m} \times 1,0 \mathrm{~m}$. As demais práticas culturais obedeceram às necessidades da cultura (Filgueira, 2008).

Sempre no horário da manha, as flores foram 
etiquetadas, com fitas coloridas, no dia de sua antese e as colheitas dos frutos realizadas em conformidade com as idades pré-estabelecidas para os tratamentos. Após a colheita, os frutos foram levados ao Laboratório de Análise de Sementes, e deixados em repouso por sete dias à temperatura ambiente em torno de $28{ }^{\circ} \mathrm{C}$. Após esse período, as sementes foram extraídas e, em seguida, colocadas para determinar o teor de água e a massa seca. A parte restante das sementes foi lavada e submetida à assepsia com solução de hipoclorito de sódio a $1 \%$, durante três minutos, para eliminação de contaminantes, e posta para secar à temperatura ambiente $\left(28-30^{\circ} \mathrm{C}\right)$ no laboratório por 12 horas (Kikut, 2005).

A qualidade das sementes foi avaliada pelos seguintes testes e/ou determinações:

Teor de água - realizado com duas repetições de 5 g de sementes por tratamento, pelo método estufa a 105 $\pm 3{ }^{\circ} \mathrm{C}$, durante 24 horas de acordo com as Regras para Análise de Sementes - RAS (Brasil, 2009) e os resultados expressos em percentagem.

Massa seca das sementes - determinada com duas repetições de 10 sementes por tratamento pelo método de secagem em estufa a $105 \pm 3{ }^{\circ} \mathrm{C}$, durante 24 horas (Brasil, 2009), sendo os resultados expressos em g 100 sementes ${ }^{-1}$.

Germinação - conduzida com quatro repetições de 50 sementes, distribuídas a $1,0 \mathrm{~cm}$ de profundidade em bandejas plásticas contendo areia esterilizada, umedecida a $60 \%$ da capacidade de retenção e mantidas em laboratório à temperatura ambiente de $28-30^{\circ} \mathrm{C}$ (Brasil, 2009).

Primeira contagem da germinação - realizada em conjunto com o teste de germinação, determinando-se a percentagem de plântulas normais no quarto dia após a semeadura (Brasil, 2009).

Índice de velocidade de emergência de plântulas (IVE) - quatro repetições de 50 sementes foram semeadas a 1,0 cm de profundidade em bandejas plásticas contendo areia lavada e esterilizada, e umedecida a $60 \%$ da capacidade de retenção. As bandejas foram mantidas em laboratório à temperatura de $28-30{ }^{\circ} \mathrm{C}$, sendo feitas contagens diárias do número de plântulas emersas até o décimo dia e os cálculos realizados segundo recomendação de Maguire (1962).

Envelhecimento acelerado (EA) - seguiu-se as recomendações de Cassaroli, (2006). Utilizou-se caixas de plástico para germinação $(11 \times 11 \times 3 \mathrm{~cm})$, possuindo em seu interior uma bandeja com tela de alumínio onde as sementes foram distribuídas de maneira a formar uma camada uniforme. Dentro de cada caixa foram adicionados $40 \mathrm{~mL}$ de água destilada. As caixas tampadas permaneceram no interior da câmara, a $41{ }^{\circ} \mathrm{C}$, por 48 horas. Decorrido este período, quatro repetições de 50 sementes foram submetidas ao teste de germinação em folhas de papel germitest, umedecidas com água destilada a 2,5 vezes o peso seu peso seco e colocadas em germinador a temperatura de $25{ }^{\circ} \mathrm{C}$, efetuando-se a contagem única das plântulas normais no quarto dias após a semeadura.

Teor de água após o período de envelhecimento acelerado - utilizou-se duas subamostras de $5 \mathrm{~g}$ de sementes por tratamento, adotando-se o método estufa a $105 \pm 3{ }^{\circ} \mathrm{C}$, durante 24 horas (Brasil, 2009) e os resultados foram expressos em percentagem.

As características avaliadas foram submetidas à análise de variância utilizando-se o software ESTAT e análise de regressão com o software Table Curve (Jandel, 1991).

\section{RESULTADOS E DISCUSSÃO}

O teor de água nas sementes, inicialmente elevado, apresentando aos 20 DAA 76\% e durante o processo de maturação fisiológica verificou-se decréscimo lento, atingindo 50\% de água aos 60 DAA e, mantendo-se estável a partir dos 50 DAA (Figura 1A).

Esse elevado teor de água inicial na semente pode ser justificado pela necessidade da mesma sintetizar e metabolizar materiais de reserva que ocorrem em meio aquoso. No entanto, por se tratar de fruto carnoso, as sementes ao atingirem a maturidade fisiológica mantêm o teor de água elevado, tendendo a estabilidade, próximo a maturidade fisiológica (Marcos Filho, 2005). Nesse tipo de fruto, as sementes, normalmente não passam pela fase de rápida desidratação, nem sofrem grandes oscilações no seu teor de água em função da umidade relativa do ar (Dias, 2001). O aspecto que leva a esse fato é a própria constituição do fruto carnoso com espessa polpa, mantendo elevado o teor de água em seu interior, assim como, diminuindo a interferência do aumento da umidade relativa do ar ao longo do experimento. Resultados semelhantes foram verificados por Alvarenga et al. (1991), trabalhando com abóbora italiana, em que os frutos armazenados por seis dias apresentaram um teor de água nas sementes de $81 \%$ aos 25 DAA e $48 \%$ aos 65 DAA. Do mesmo modo, em maxixe, o teor de água se manteve alto no final do período avaliado, aos 40 DAA com $50 \%$ (Medeiros et al., 2010), confirmando os resultados obtidos com os frutos de abobrinha. 


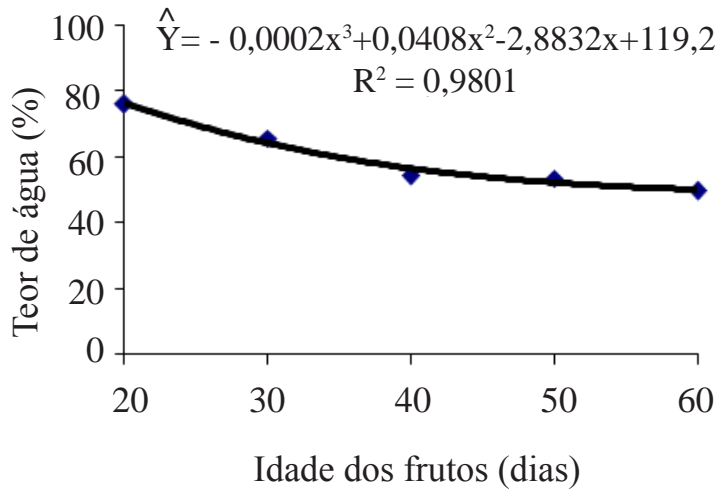

(A)

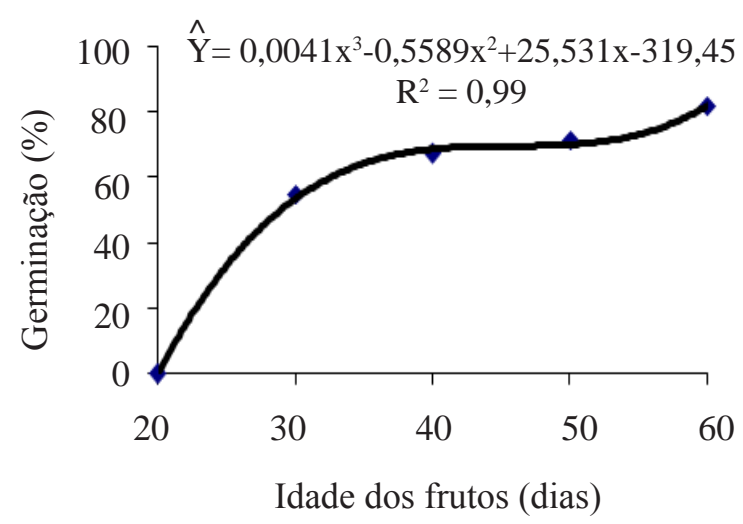

(C)

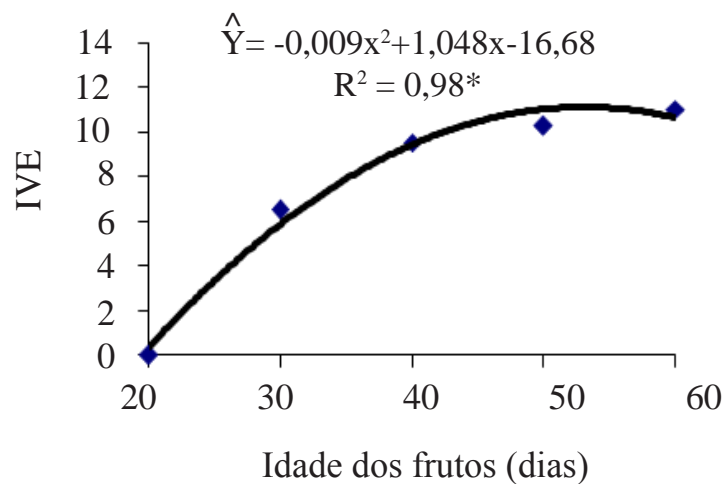

(E)

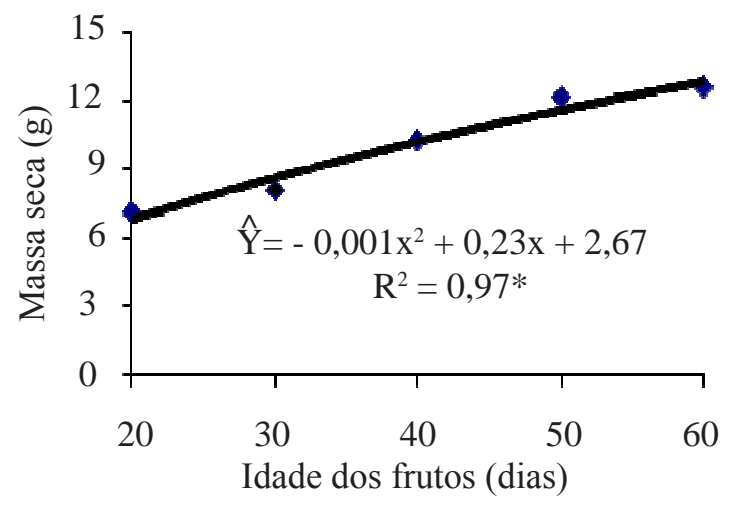

(B)

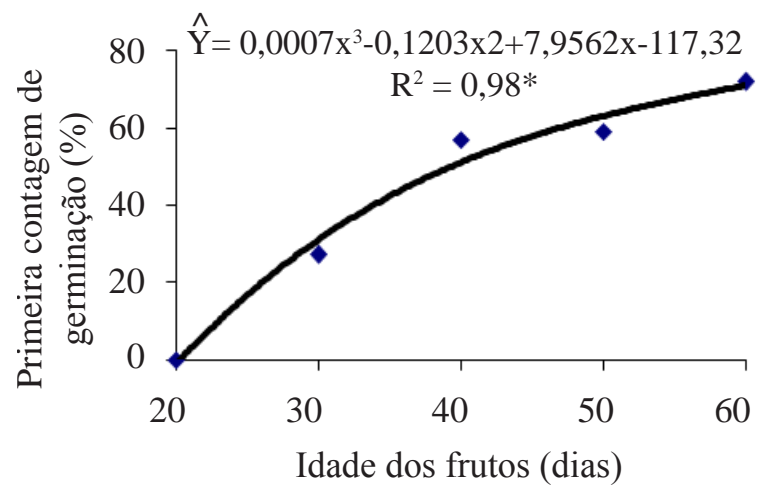

(D)

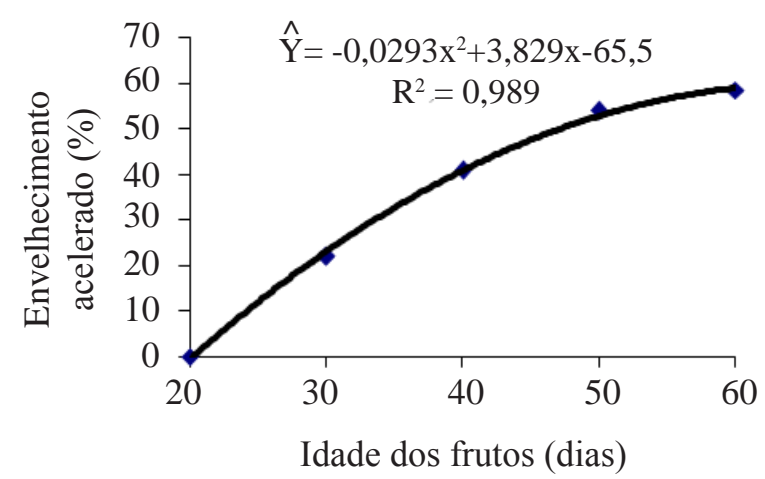

(F)

FIGURA 1. Teor de água (A), massa seca (B), primeira contagem de germinação (C), germinação (D), IVG (E) e envelhecimento acelerado (F) de sementes de abobrinha, cv Menina Brasileira, em função da idade dos frutos. 
A massa seca (Figura 1B) teve comportamento inversamente proporcional ao teor de água das sementes (Figura 1A), crescente durante todo o período avaliado, com valor mínimo de 6,8 g 100 sementes $^{-1}$ aos 20 DAA e máximo de 11,8 g 100 sementes $^{-1}$ aos 60 DAA. O maior incremento de massa seca foi observado entre o período de 20 a 40 DAA, com valor médio estimado de 3,7 g 100 sementes $^{-1}$, representando o total de $74 \%$ da massa seca acumulada. Comportamento semelhante foi verificado por Costa et al. (2006), trabalhando com frutos de abóbora híbrida, onde as sementes ganharam massa até aos 50 DAA.

Esse acúmulo de massa seca na semente em formação se faz, inicialmente, de maneira lenta, pois logo após a fecundação do óvulo ocorre o processo de divisão das células para depois se desenvolverem, geralmente esse período de multiplicação celular é de curta duração. Em seguida inicia-se uma fase de rápido acúmulo de massa seca, que é intensificada até atingir seu máximo, o que geralmente coincide com o ponto de maturidade fisiológica (Carvalho e Nakagawa, 2000).

A germinação das sementes (Figura $1 \mathrm{C}$ ) foi nula aos 20 DAA, iniciando-se na segunda coleta de frutos aos 30 DAA, quando apresentou $54 \%$ de sementes germinadas. O percentual de germinação foi crescente, observando-se certa estabilidade entre 40 e 50 DAA, sendo este período considerado como uma possível indicação da maturidade das sementes, chegando a atingir o máximo de $86 \%$ aos 60 DAA e, também, coincidindo com maior quantidade de massa seca (Figura 1B), menor teor de água (Figura 1A) e maior percentagem de germinação no teste de primeira contagem (Figura 1D).

Provavelmente, um dos possíveis fatores que atuaram impedindo a germinação das sementes aos 20 DAA, foi à presença de inibidores, como o ácido abscísico, que em grandes concentrações, impede a germinação precoce das sementes favorecendo o acúmulo de suas reservas, assim como a imaturidade do embrião (Kermode, 2005; Marion-Poll, 1997). Vidigal et al. (2009), trabalhando com pimenta, observaram germinação das sementes provenientes de frutos colhidos aos 40 DAA, sendo crescente até os 70 dias após a antese, com média de $91 \%$. Confirmando os resultados obtidos por Costa et al. (2002), onde as sementes de abóbora híbrida alcançaram o seu potencial máximo de germinação no período de 60 a 70 dias.

Com relação à primeira contagem de germinação (Figura 1D), foi nula aos 20 DAA. O início da germinação ocorreu aos 30 DAA mantendo-se crescente até aos 60 DAA, com valor máximo de $78 \%$ e permanecendo estável durante o período de 40 a 50 DAA, corroborando com o verificado no teste de germinação (Figura 1C). Resultados semelhante foram observados por Vidigal et al. (2006), com sementes de tomate, em que observaram melhor qualidade fisiológica para as sementes obtidas de frutos colhidos aos 50 e 60 DAA. Em pimenta, o maior percentual de primeira contagem de germinação ocorreu aos 70 DAA, com sete dias de repouso, correspondendo a $82 \%$ (Vidigal et al., 2009).

No tocante ao índice de velocidade de emergência (Figura 1E), verificou-se germinação nula aos 20 DAA, portanto, sendo iniciada aos 30 DAA, onde se verificou índice de 6,7, o qual sofreu acréscimos até os 60 DAA $(13,8)$, estabilizando-se nas últimas três coletas. Comportamento semelhante foi observado em sementes de pepino por Barbedo et al. (1997).

As percentagens médias do teor de água das sementes após o período do de envelhecimento acelerado variaram de 0,6 a 2,0 pontos percentuais (Tabela 2). Um dos principais indicadores da uniformidade das condições do envelhecimento acelerado é o teor de água das sementes ao final do teste, pois variações de 3 a 4\% entre amostras são consideradas toleráveis (Marcos Filho, 1999); portanto, verificou-se que a variação máxima encontrada foi de 2,0\%, ou seja, abaixo dos limites toleráveis.

$\begin{gathered}\text { TABELA 2. Teores de água de sementes de abobrinha, } \\
\text { cv. Menina Brasileira, obtidos após o } \\
\text { período de envelhecimento acelerado. }\end{gathered}$
\begin{tabular}{cc} 
Idade dos frutos & Teor de água após o envelhecimento \\
(DAA) & acelerado (\%) \\
\hline 20 & 48,8 \\
30 & 48,2 \\
40 & 47,7 \\
50 & 47,0 \\
60 & 46,8 \\
\hline
\end{tabular}

O teste de envelhecimento acelerado apresentou germinação aos 30 DAA de 23\%, e aos 60 DAA chegou a atingir $59 \%$, indicando alto potencial fisiológico das sementes de abobrinhas (Figura 1F). Mesmo tendo sido 
expostas a níveis adversos de temperatura e umidade relativa, acelerando o processo de deterioração das mesmas. Esses resultados confirmam os obtidos por Medeiros et al. (2010), com sementes de maxixe, onde observaram que no envelhecimento acelerado a germinação aumentou durante todo o período avaliado com um ligeiro decréscimo no final do período, obtendo máxima germinação de $63 \%$ aos 30 DAA.

De modo geral, o vigor das sementes aumentou gradativamente ao longo do processo de maturação, o que foi percebido com o teor de água (Figura 1A), massa seca (Figura 1B), germinação (Figura 1C), primeira contagem de germinação (Figura 1D) e índice de velocidade de emergência (Figura 1E), sugerindo que as sementes estão completamente formadas no final do período avaliado.

\section{CONCLUSÕES}

As sementes de abobrinha, cultivar Menina Brasileira, atingem a maturidade fisiológica no período entre 50 e 60 DAA, o que corresponde ao ponto de máxima germinação e vigor, podendo sua colheita ser realizada durante esse período sem dano para as sementes.

\section{REFERÊNCIAS}

ALVERENGA, E.M.; SILVA, R.F. da; ARAUJO, E.F.; LEIRO, L.S. Maturação fisiológica de sementes de abóbora italiana. Revista Brasileira de Sementes, v.13, n.2, p.147150, 1991.

BARBEDO, C.J.; NAKAGAWA, J.; BARBEDO, A.S.C.; ZANIN, A.C.W. Qualidade fisiológica de sementes de pepino $\mathrm{Cv}$ pérola em função da idade e do tempo 35 de repouso pós-colheita dos frutos. Pesquisa Agropecuária Brasileira, v.32, n.9, p.1-7, 1997.

BEE, R.A.; BARROS, A.C.S.A. Sementes de abóbora armazenadas em condições de vácuo. Revista Brasileira de Sementes, v.21, n.2, p.120-126, 1999.

BRASIL. Ministério da Agricultura, Pecuária e Abastecimento. Regras para análise de sementes. Ministério da Agricultura, Pecuária e Abastecimento. Secretaria de Defesa Agropecuária. Brasília, DF: Mapa/ ACS, 2009. 395p.

CARMO FILHO F do.; ESPÍNOLA SOBRINHO J.; MAIA NETO J.M. Dados climatológicos de Mossoró: um município do semi-árido nordestino. Mossoró: ESAM. 1991, 121p. (Coleção Mossoroense, C, 30).
CARVALHO, N.M.; NAKAGAWA, J. Sementes: ciência, tecnologia e produção. 4.ed. Jaboticabal: FUNEP, 2000. 422p.

CASAROLI, D.; GARCIA, D.C.; MENEZES, N.L.; MUNIZ, M.F.B.; MANFRON, P.A. Testes para determinação do potencial fisiológico de sementes de abóbora. Acta Scientiarum Agronomy, v.31, n.2, p.337343, 2009.

CASAROLI, D.; GARCIA , D.C.; MENEZES , N.L.; MUNIZ, M.F.B.; BAHRY, C.A. Teste de envelhecimento acelerado em sementes de abóbora. Revista da FZVA, v.13, n.2, p.97-107, 2006.

CAVALCANTI, F.J. de A. Recomendações de adubação para o estado de Pernambuco ( $2^{\mathrm{a}}$ aproximação). 2.ed. Recife, IPA, 1998. 189p.

COSTA, C.J.; CARMONA, R.; NASCIMENTO, W.M. Idade e tempo de armazenamento de frutos e qualidade fisiológica de sementes de abóbora híbrida. Revista Brasileira de Sementes, v.28, n.1, p.127-132, 2006.

COSTA, C.J.; NASCIMENTO, W.M.; CARMONA, R. Efeito da idade e do armazenamento dos frutos na qualidade fisiológica de sementes híbridas de abóbora. Horticultura Brasileira, v.20, n.2, p.1-4, 2002. Suplemento 2.

DIAS, D.C.F.S.; RIBEIRO, F.P.; DIAS, L.A.S.; SILVA, D.J.H.; VIDIGAL, D.S. Maturação de sementes de tomate em função da ordem de frutificação na planta. Revista Ceres, v.53, n.308, p.446-456, 2006.

DIAS, D.C.F.S. Maturação fisiológica de sementes: o processo. Seed News, v.5, n.6, p.22-24, 2001.

ESTAT 2.0 Sistema de análise estatística. Jaboticabal: Pólo Computacional - Departamento de Ciências Exatas UNESP, 1992.

FILGUEIRA, F.A.R. Novo manual de olericultura: agrotecnologia moderna produção e comercialização de hortaliças. 3.ed. Viçosa, MG: UFV, 2008. 421p.

JANDEL SCIENTIFIC. Table curve: curve fitting software. Corte Madera, 1991. 280p.

KERMODE, A.R. Role of abscisic acid in seed dormancy. Journal of Plant Growth Regulation v.24, p.319-344, 2005.

KIKUTI, A.L.P.; MENTEN, J.O.M.; MORAIS, M.H.D.; OLIVEIRA, S.R.S. Interferência da assepsia em sementes de pimentão submetidas ao teste de envelhecimento acelerado. Revista Brasileira de Sementes, v.27, n.2, p.44-49, 2005. 
MAGUIRE, J.D. Speeds of germination-aid selection and evaluation for seedling emergence and vigor. Crop Science, v.2, p.176-177, 1962.

MARCOS FILHO, J. Teste de envelhecimento acelerado. In: KRZYZANOWSKI, F.C.; VIEIRA, R.D.; FRANÇANETO, J.B. (Ed.). Vigor de sementes: conceitos e testes. Londrina: ABRATES, 1999. cap.3, p.1-24.

MARCOS FILHO, J. Fisiologia de sementes de plantas cultivadas. Piracicaba: Fealq, 2005. 495p.

MARION-POLL, A. ABA and seed development. Elsevier Science Ltd. v.2, p.447-448, 1997.

MEDEIROS, M.A.; GRANGEIRO, L.C.; TORRES, S.B.;
FREITAS, A.V.L. Maturação de sementes de maxixe maturação fisiológica de sementes de maxixe (Cucumis anguria L.). Revista Brasileira de Sementes. v.32, n.3, p.17-24, 2010.

VIDIGAL, D. de S; DIAS, D.C.F. dos S.; PINHO, E.V.R.V.; DIAS. L.A.S.; Alterações fisiológicas e enzimáticas durante a maturação de sementes de pimenta (Capsicum annuum L.). Revista Brasileira de Sementes, v. 31, n.2, p.129136, 2009.

VIDIGAL, D. de S.; DIAS, D.C.F. dos S.; NAVEIRA, D. dos S.P.C.; ROCHA, F.B.; BHERING, M.C. Qualidade fisiológica de sementes de tomate em função da idade e do armazenamento pós-colheita dos frutos. Revista Brasileira de Sementes, v.28, n.3, p.87-93, 2006. 